\title{
ANALYSIS OF EQUILIBRIUM METHODS FOR THE COMPUTATIONAL MODEL OF THE MARK-IV ELECTR OREFINER
}

\author{
RILEY CUMBERLAND ${ }^{1}$, ROBERT HOOVER ${ }^{* 2}$, SUPATHORN PHONGIKAROON ${ }^{2}$, and MAN-SUNG YIM ${ }^{1}$ \\ ${ }^{1}$ North Carolina State University, Department of Nuclear Engineering, Campus Box 7909, \\ North Carolina State University, Raleigh, NC 27695-7909 \\ ${ }^{2}$ University of Idaho, Department of Chemical and Materials Engineering, Nuclear Engineering Program, \\ Center for Advanced Energy Studies, 995 University Boulevard, Idaho Falls, Idaho 83402 \\ "Corresponding author. E-mail : supathor@uidaho.edu
}

Received January 26, 2011

Accepted for Publication April 23, 2011

Two computational methods for determining equilibrium states for the Mark-IV electrorefiner (ER) have been assessed to improve the current computational electrorefiner model developed at University of Idaho. Both methods were validated against measured data to better understand their effects on the calculation of the equilibrium compositions in the ER. In addition, a sensitivity study was performed on the effect of specific unknown activity coefficients-including sodium in molten cadmium, zirconium in molten cadmium, and sodium chloride in molten LiCl-KCl. Both computational methods produced identical results, which stayed within the $95 \%$ confidence interval of the experimental data. Furthermore, sensitivity to unavailable activity coefficients was found to be low (a change in concentration of less than $3 \mathrm{ppm}$ ).

KEYWORDS : Stoichiometric Method, Equilibrium, Computational Model, Mark-IV Electrorefiner, Molten Salt, Cadmium Pool, Zirconium

\section{INTRODUCTION}

Spent driver fuel from the Experimental Breeder Reactor-II (EBR-II), a sodium cooled fast reactor located in southeastern Idaho [1], is being processed in the MarkIV (Mk-IV) electrorefiner (ER) at Idaho National Laboratory (INL) [2], formerly Argonne National Laboratory-West. The Mk-IV ER is a cylindrical, stainless steel vessel $1 \mathrm{~m}$ across and about $1 \mathrm{~m}$ in height operated at $773 \mathrm{~K}$ in an argon atmosphere. The electrolyte is a $\mathrm{LiCl}-\mathrm{KCl}$ eutectic mixture containing several $\mathrm{w} \% \mathrm{UCl}_{3}$, which floats on an immiscible pool of liquid $\mathrm{Cd}$ approximately $10 \mathrm{~cm}$ deep (see Fig. 1). Each anode assembly consists of 4 baskets arranged in a cruciform pattern with a diameter of $25 \mathrm{~cm}$. Prior to operation, anode baskets are loaded with chopped EBR-II driver fuel, consisting of a $\mathrm{U}-\mathrm{Zr}$ alloy encased in a stainless steel cladding and exposed on the ends. The fuel alloy was bonded to the cladding with sodium metal. Each cathode is a steel mandrel to which uranium adheres after the electrorefining process begins [3].

Upon insertion of a fresh anode into the system, the more active metals in the chopped fuel segments are oxidized by the more noble salt species in the molten salt to produce noble metal [3]. The reduced metal may adhere to the anode or-being denser than the salt-may fall to the bottom of the ER and dissolve into the $\mathrm{Cd}$ pool. That, in combination with changes in the distribution of species in the salt, initiates reactions between the pool and the salt. In addition, once noble metals dissolved in the pool exceed their solubility limit, they will come out of solution and precipitate in the pool forming "pool precipitate" [4, $5,6]$. It is this complex series that needs to be considered in developing the predictive computational model.

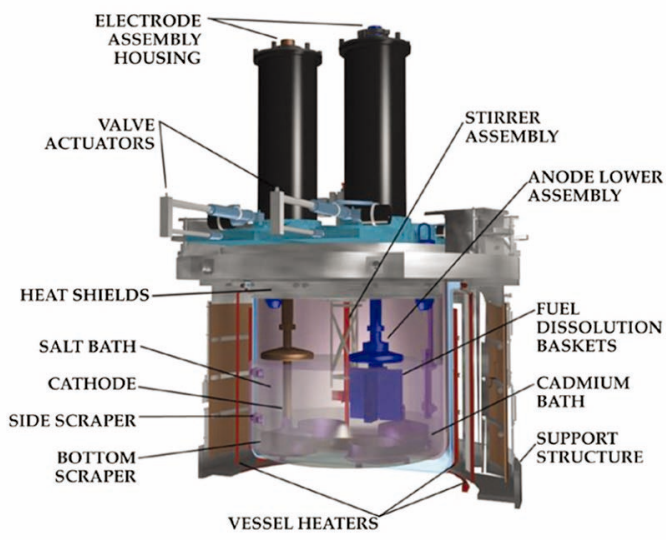

Fig. 1. The Mk-IV Electrorefiner 
The method for calculating equilibrium is significant in the initiation stage of the modeling process. In previous work, equilibrium calculations for the electrorefiner were performed using individual equations for each possible reaction [7]. Ackerman (1989) took a piecewise approach to the problem in his algorithm-PYRO-by first accounting for all the reactions that should occur to completion and later employing a recursive algorithm to determine equilibrium among the remaining species [8]. Nawada and Bhat (1998) reported a similar approach by modeling the thermodynamic reactions between two liquid cadmium electrodes and a molten salt bath using 10 equations [4]. Their method only accounted for $U$ and $\mathrm{Pu}$ transport and solubility limits in the liquid electrodes.

Vaden (2006) took a uniform approach to the process by employing matrix style equilibrium computations $[9,10]$. These methods are documented in detail by Smith and Missen [11]. Equilibrium methods were grouped into two classifications based on how stoichiometry was handled. In a stoichiometric method (SM), Gibbs free energy is minimized with stoichiometric relations being enforced implicitly under a clever definition of the independent variable. In contrast to the first method, a non-stoichiometric method (NSM) enforces stoichiometric relations through various other means; that is, it uses a measure of species population as the independent variable [11]. Vaden reported results showing comparisons between both methods and experimental data [9]. Those results revealed that the SM predicted results accurately while the NSM did not. It was stated in that work that a possible reason the NSM performed poorly was due to the NSM disregarding the separation of the anode and pool. The NSM method allowed species to be wrongly transported between the anode and pool in that model [9]. However, his implementation of the SM was later refined to include solubilities in the $\mathrm{Cd}$ pool, and it was used to accurately predict electrorefiner inventories [10].

Hoover and co-workers (2010) applied a simple equilibrium method to predict the chemistry in the MkIV prior to operation by only accounting for one reactionplutonium reacting with $\mathrm{UCl}_{3}$ in the electrolyte and dissolving out of the spent fuel basket [12]. This method was applied to the current ER computational model developed at the University of Idaho [12, 13]. However, the actual system as described above is complex thus providing a motivation to improve the equilibrium method used in the model. Therefore, the SM and NSM have been reexamined and reanalyzed in this study. The SM and the NSM are implemented as part of a larger method designed to account for the physical separation between the anode and the pool. This was done because Vaden proposed that the failure of the NSM was due to its not accounting for that separation [9]. The current work is compared to Vaden's experimental data. In addition, to ensure accurate results, the sensitivity to inputs is examined for uncertain parameters like the activity coefficients of $\mathrm{Na}$ and $\mathrm{Zr}$. In an effort to ensure robustness of the method, extreme conditions have been applied and output values were examined to determine their accuracy. This study will enhance a general understanding of the Mk-IV ER process, aid in the design of future generations of ERs, and help evaluate proliferation resistance of the system.

\section{THEORY}

In general, systems approach equilibrium by moving to the lowest energy state possible. Therefore, minimization of a system's Gibbs free energy is a good way to compute equilibrium concentrations. Gibbs free energy for the system $(G)$ is given by

$$
G=\sum_{a}^{A} \sum_{e}^{E} n_{e a} \mu_{e a}
$$

where $a$ is the phase index, $A$ is the total number of phases, $e$ is the species index, $E$ is the total number of species in each phase, $n$ is the number of moles, and $\mu$ is the chemical potential, which is given by $[9,11,14]$ :

$$
\mu_{e a}=\mu_{e a}^{0}+R T \ln \left(\frac{\gamma_{e a} n_{e a}}{\sum_{e}^{E} n_{e a}}\right) \text {. }
$$

Here, $R$ is the gas constant, $T$ is the absolute temperature, $\gamma$ is the species activity coefficient, and $\mu_{e a}^{0}$ is the free energy of formation, or the standard state free energy.

The solubility limit is important in the cadmium pool. Over the course of ER operation, material is scraped off of the cathode and dissolves in the cadmium. In addition, precipitate from reactions between the salt and the anode may fall into the pool and dissolve. Due to this stream of material entering the pool, the solubility limit for various compounds may be reached. When it is reached, a solid "pool precipitate" forms in the cadmium pool. It is important to distinguish between the metallic precipitate formed in the salt, and the intermetallic "pool precipitate" formed in the pool.

\section{MATHEMATICAL MODEL}

Due to the problem encountered in Vaden's work with the NSM implementation [9], it was decided to split the equilibrium problem into smaller parts in the current work. The split up algorithm is shown in Fig. 2 and will be referred to as the master method. It is an iterative method where each step incrementally approaches equilibrium.

There are four steps in the master method. Step 1 computes equilibrium compositions for the pool and the molten salt, ignoring the anode and the pool precipitate. Either the SM or NSM can be used for Step 1. Step 2 
accounts for precipitation and dissolution of species in the pool using solubility limits. Step 3 is similar to Step 1, except that the anode-molten salt interface is considered. Again, either the SM or the NSM will be used. In Step 4, any material that is in excess of the initial anode content is considered to be precipitate, and it is moved into the cadmium pool. This step can be easily modified to only allow a specified fraction of each species to adhere to the anode, rather than to precipitate into the cadmium pool. Steps 1-4 are applied until convergence is reached.

The main limitation to the above model is that if there is not sufficient material for reactions to completely occur, only one interface can be perturbed prior to the equilibrium calculation. For example, consider the master method being used to compute the equilibrium of an ER with an anode of 5 moles $U$, an electrolyte containing 3 moles $\mathrm{CdCl}_{2}$, and a pool containing 5 moles of $\mathrm{U}$. The $\mathrm{CdCl}_{2}$ will react with the $U$ in the pool, and the $U$ in the anode, however not all of the $U$ will react. Therefore it is impossible to determine the amount of $U$ left in the anode, or the amount of $U$ left in the pool without a model that incorporates some additional parameters such as rate constants. Such a model is, however, beyond the scope of this work.

The NSM implementation of the master method presented in this paper consists of the master method, with the NSM applied in Steps 1 and 3. The NSM minimizes $G$ as a function of species population [11] with

$$
\min G=\sum_{a}^{A} \sum_{e}^{E} n_{e a} \mu_{e a}
$$

such that

$$
\sum_{a}^{A} \sum_{e}^{E} n_{e a} z_{e a}=T_{m}
$$

where $T_{m}$ is to the total number of moles of each element in the system and $z_{e a}$ is the entry in the formula matrix for the interface at which the computation is taking place [9]. An example formula matrix for the anode-salt interface is shown in Table 1. Each column and row represent a compound and an element, respectively. The number in each cell is the number of atoms of the element in the compound and empty cells represent zeros. The NSM implementation used the fmincon function in MATLAB to minimize the Gibbs energy.

Table 1. Formula Matrix for the Anode-salt Interface.

\begin{tabular}{c|c|c|c|c|c|c|c|c}
\hline & \multicolumn{5}{|c|}{ Anode } & \multicolumn{4}{c}{ Electrolyte } \\
\hline & $\mathbf{L i}$ & $\mathbf{K}$ & $\mathbf{C d}$ & $\mathbf{U}$ & $\mathbf{L i C l}$ & $\mathbf{K C l}$ & $\mathbf{C d C l}_{2}$ & $\mathbf{U C l}_{3}$ \\
\hline $\mathbf{L i}$ & 1 & & & & 1 & & & \\
\hline $\mathbf{K}$ & & 1 & & & & 1 & & \\
\hline $\mathbf{C d}$ & & & 1 & & & & 1 & \\
\hline $\mathbf{U}$ & & & & 1 & & & & 1 \\
\hline $\mathbf{C l}$ & & & & & 1 & 1 & 2 & 3 \\
\hline
\end{tabular}

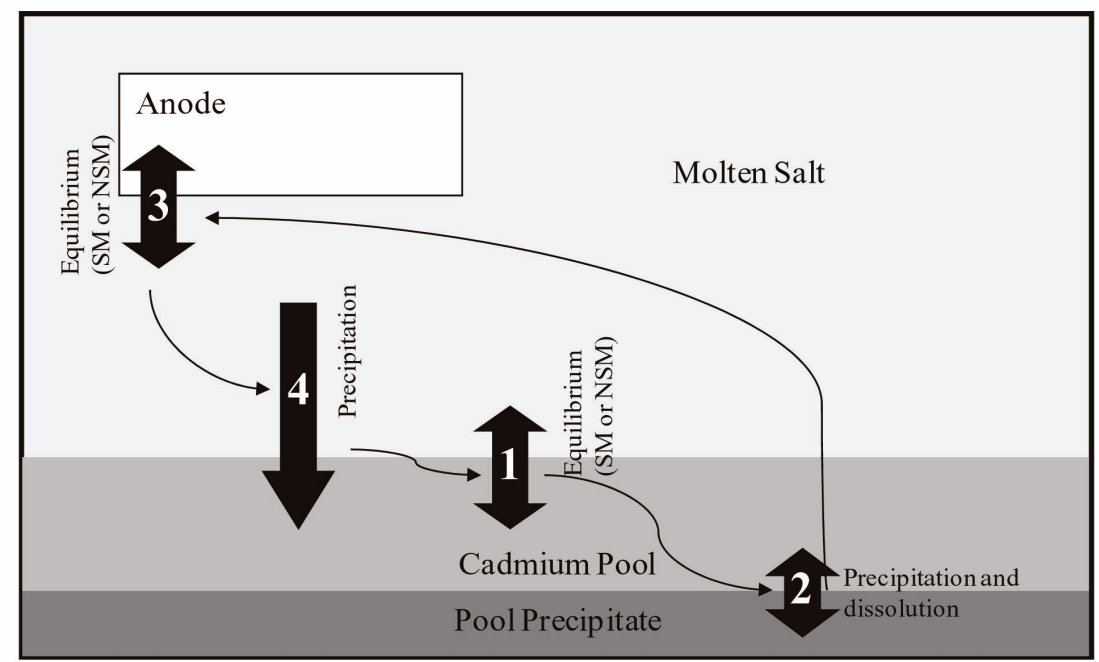

Fig. 2. The Master Method, with Wide Arrows Depicting How Mass is Transferred by Each Step and Narrow Arrows Showing the Program Flow. The White Numbers in the Wide Arrows Represent Computational Steps in the Model. Steps 1 and 3 can Employ Either the SM or the NSM. The NSM Implementation of the Master Method uses the NSM to Compute Steps 1 and 3, and the SM Implementation of the Master Method uses the SM to Compute Steps 1 and 3. 
The SM implementation is simply the master method with the SM applied in steps 1 and 3. The SM minimizes the Gibbs free energy function as a function of extent of reaction [9]. Extents of reaction $\left(\delta \epsilon_{r}\right)$ are employed to implicitly account for the stoichiometry of the system in the independent variable, without having to apply external constraints on the objective function. The stoichiometric method increments toward the minimum $G$ by solving

$$
\left(\frac{\partial^{2} G}{\partial \epsilon_{r}^{2}}\right) \cdot \delta \epsilon_{r}=-\left(\frac{\partial G}{\partial \epsilon_{r}}\right)
$$

for the extents of reaction. The derivative of $G$ is calculated as

$$
\left(\frac{\partial G}{\partial \epsilon_{r}}\right)=\sum_{\mathrm{a}}^{\mathrm{A}} \sum_{\mathrm{e}}^{\mathrm{E}}\left(v_{e a r} \mu_{e a}\right)=0 \text { for } r=1,2 \ldots R \text { reactions, }
$$

where $v$ is an entry in the stoichiometric matrix. It is possible to linearly transform extent of reaction into species population by

$$
n_{e a}=n_{e a}^{0}+\sum_{r}\left(v_{e a r} \cdot \delta \epsilon_{r}\right)
$$

An example stoichiometric matrix for the anode-salt interface is shown in Table 2 with the following chemical reactions:

$$
\begin{aligned}
& U^{(s)}+3 L i C l^{(l)} \leftrightarrow 3 L i^{(s)}+U C l_{3}^{(l)}, \\
& U^{(s)}+3 K C l^{(l)} \leftrightarrow 3 K^{(s)}+U C l_{3}^{(l)},
\end{aligned}
$$

and

\begin{tabular}{|c|c|c|c|c|}
\hline & & Rx1 & $\operatorname{Rx} 2$ & Rx3 \\
\hline \multirow{4}{*}{ 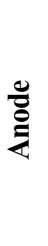 } & $\mathbf{L i}$ & -3 & & \\
\hline & $\mathbf{K}$ & & -3 & \\
\hline & Cd & & & -3 \\
\hline & $\mathbf{U}$ & 1 & 1 & 2 \\
\hline \multirow{4}{*}{ 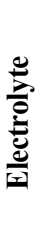 } & LiCl & 3 & & \\
\hline & $\mathrm{KCl}$ & & 3 & \\
\hline & $\mathrm{CdCl}_{2}$ & & & 3 \\
\hline & $\mathrm{UCl}_{3}$ & -1 & -1 & -2 \\
\hline
\end{tabular}

$$
2 U^{(s)}+3 C d C l_{2}^{(l)} \leftrightarrow 3 C d^{(s)}+2 U C l_{3}^{(l)}
$$

Each column and row represent a reaction and a compound,

Table 2. Stoichiometric Matrix for Anode-salt Interface. respectively. The numbers in the cells are the stoichiometric coefficients for compounds involved in the reaction. Zeros are represented by empty cells. The version of the SM outlined by Kress [14] was used to implement the SM in this study. This version of the SM includes shuffling the stoichiometric matrix using linear column operations to avoid a singular matrix. This also helps ensure that the method is not overly constrained. Negative species concentrations were avoided by testing for negativity on each iteration step, and scaling back extents of reaction accordingly.

When the solubility limit of a metal $(M)$ in the pool is exceeded, the reaction

$$
M^{(C d)}+B C d^{(C d)} \rightarrow M C d_{B}^{(s)}
$$

occurs to form the solid intermetallic- $-\mathrm{MCd}_{\mathrm{B}}$. In the case of uranium, the pure metal precipitates, so the stoichiometric coefficient $(B)$ is considered to be 0 . Solubility limits are shown in Table 3. It was assumed that elements having no solubility limits listed in Table 3 do not ever occur in a high enough concentration to precipitate out of the pool. The solubility formulation is based on the fact that the concentration of a metal dissolved in the cadmium will always be less than or equal to the solubility limit. Thus, the limiting condition can be determined as

$$
N_{M}^{\prime}=S N_{C d}^{\prime},
$$

where $N_{M}$ represents the updated amount of dissolved metal in moles and $N_{C d}$ is the updated amount of metallic $\mathrm{Cd}$ in moles. Additionally, it was assumed that any excess will react with the cadmium and precipitate, so that

$$
\mathrm{B}\left(N_{\mathrm{M}}^{\prime}-N_{\mathrm{M}}^{0}\right)=N_{C d}^{\prime}-N_{C d}^{0}
$$

where $N_{M}{ }^{0}$ denotes the previous amount of dissolved metal in moles (given by step 1) and $N_{C d}{ }^{0}$ is the previous amount of metallic Cd in moles. $S$ represents moles of solute per mole of solvent at saturation. Solving Eqs. (12) and (13) for $N_{M}$ ' yields

$$
N_{M}^{\prime}=N_{M}^{0}+\frac{S N_{C d}^{0}-N_{M}^{0}}{1-S B}
$$

Given the result from Eq. (14), one can use simple mass balances to solve for the final amount of pool precipitate and the final amount of molten $\mathrm{Cd}$ in the pool. The main limitation of this method is that the solubility limit for one metal does not depend on the concentrations of other metals.

\section{METHODS}

To verify the SM and the NSM implementations, experimental data reported by Vaden [9] was used, and it 
will be referred to as Case 1. Initially, the anode contained 84.08 moles $\mathrm{U}$, while the salt contained 4601 moles $\mathrm{LiCl}$, 3159 moles $\mathrm{KCl}$, and 126.4 moles $\mathrm{CdCl}_{2}$ [9]. Activity coefficients, standard Gibbs energies, and solubilities from Table 3 were employed in the calculations. The two methods were compared to the experimental data. The error in the model predictions was calculated based on the following equation:

$$
\text { Error }=\left|\frac{\text { Experimental } w t \%-\text { Computed } w t \%}{\text { Experimental } w t \%}\right| \times 100
$$

Next, the two methods were compared against each other using Cases 2 and 3 which were based on the same ER run input data as in Ref. 12 , both with initial anode contents of $71.6 \mathrm{~mol} \% \mathrm{U}, 25.3 \mathrm{~mol} \% \mathrm{Zr}$, and $0.3 \mathrm{~mol} \%$ $\mathrm{Pu}$, with the remainder being other elements. The initial salt composition was $55.8 \mathrm{~mol} \% \mathrm{LiCl}, 38.8 \mathrm{~mol} \% \mathrm{KCl}$, $3.5 \mathrm{~mol} \% \mathrm{NaCl}, 1.9 \mathrm{~mol} \% \mathrm{UCl}_{3}$, and $0.05 \mathrm{~mol}_{\%} \mathrm{PuCl}_{3}$. For simplicity, other elements were not considered present in the salt. $\mathrm{U}, \mathrm{Pu}, \mathrm{Zr}, \mathrm{Na}, \mathrm{Li}, \mathrm{K}$, and $\mathrm{Cd}$ were accounted for in the anode and in the pool, with their respective salts modeled in the electrolyte. Only the U, $\mathrm{PuCd}_{6}$, and $\mathrm{ZrCd}_{2}$ pool precipitates were modeled. They were considered absent from the system initially. In both adaptations of the data, the amount of $\mathrm{Pu}$ in the anode was reduced by $20 \%$ of the actual value to account for the fact that some plutonium cannot be dissolved [12]. Case 2 represents the event when ER run data has nothing dissolved in the $\mathrm{Cd}$ pool initially, while Case 3 is the extreme scenario when the system has an excessive amount of $\mathrm{Zr}(1000 \mathrm{~mol})$ initially loaded in the $\mathrm{Cd}$ pool and is included to test the limits of the model. Numerous initial loadings of dissolved $\mathrm{Zr}$ (up to 1000 moles) were used to examine the behavior of the pool precipitate portion of the model, keeping all other parameters equal to those in Cases 2 and 3.

Three input parameters shown in Table 3 were approximated as 1; these are the activity coefficients of $\mathrm{Na}$ and $\mathrm{Zr}$ in $\mathrm{Cd}$ pool and that of $\mathrm{NaCl}$ in salt. To examine the impact that this uncertainty has on the results of the two ER run cases, Case 3 has been selected and run with various values of each estimated parameter to examine the affect on the resulting value. The ranges of $\mathrm{Na}$ activity coefficients were chosen based on values reported at lower temperatures [21, 22]. Similarly, the range of $\mathrm{Zr}$ activity coefficients that were examined in the pool were chosen using a value from literature, and an unpublished value estimated from electromotive force series data [5, 23]. The effect of each activity coefficient was examined with all other values being set to those displayed in Table 3.

\section{RESULTS \& DISCUSSION}

The implementations of the SM and the NSM worked well, producing identical solutions. Run times were typically between 1 and 7 seconds on a Pentium 4 for both methods. However, convergence failed when tolerances were too tight. The failure resulted from tiny amounts of a species seeping into the salt through the anode interface, and then leaving the salt through the pool interface. Any transport of the species across the salt would be extremely slow due to the low concentration of the species in the salt, limiting the opportunity for the species to interact with the pool interface. This seepage was discounted in the code by relaxing convergence tolerances, setting them to a higher percentage. The convergence tolerances were set to $0.1 \%$ change in number for all species with a

Table 3. Model Input Parameters $[4,5,9,15,16,17,18,19,20]$. * Indicates Parameter was Estimated.

\begin{tabular}{|c|c|c|c|c|c|}
\hline Element & Chloride & $\gamma_{\text {Salt }}$ & $\gamma_{\mathrm{Cd}}$ & $\begin{array}{c}\Delta \mathbf{G}_{\mathbf{f}} \\
(\mathbf{k J} / \mathrm{mol})\end{array}$ & $\begin{array}{l}\text { Solubility Limit } \\
\text { (mole fraction) }\end{array}$ \\
\hline $\mathrm{Li}$ & $\mathrm{LiCl}$ & 0.892 & 0.0018 & -345 & \\
\hline K & $\mathrm{KCl}$ & 1.655 & 5 & -362 & \\
\hline $\mathrm{Cd}$ & $\mathrm{CdCl}_{2}$ & 0.0662 & 1 & -270 & \\
\hline $\mathrm{Zr}$ & $\mathrm{ZrCl}_{4}$ & 0.00448 & $1^{*}$ & -779.9 & 0.295 \\
\hline $\mathrm{Na}$ & $\mathrm{NaCl}$ & $1^{*}$ & $1^{*}$ & -339.74 & \\
\hline $\mathrm{Pu}$ & $\mathrm{PuCl}_{3}$ & 0.0041 & 0.000234 & -783 & 0.1838 \\
\hline $\mathrm{U}$ & $\mathrm{UCl}_{3}$ & 0.00139 & 88.73 & -692 & 0.01141 \\
\hline
\end{tabular}


Table 4. Initial, Final Experimental, Final SM and Final NSM Values for the Case 1. Negligible Error Denotes that Both the Experimental and Computed Concentrations are Less Than $0.02 \mathrm{w} \%$.

\begin{tabular}{|c|c|c|c|c|c|c|c|c|}
\hline & & Initial (w\%) & $\begin{array}{c}\text { Experimental } \\
(\mathbf{w \%})[9]\end{array}$ & $95 \%$ CI (w\%) & SM (w\%) & SM Error & $\begin{array}{l}\text { NSM } \\
(\mathbf{w} \%)\end{array}$ & NSM Error \\
\hline \multirow{4}{*}{$\begin{array}{l}\frac{0}{2} \\
\frac{0}{0} \\
\frac{0}{0} \\
\frac{0}{2}\end{array}$} & $\mathbf{L i}$ & 7.04 & 6.10 & 1.20 & 6.95 & $13.91 \%$ & 6.95 & $13.91 \%$ \\
\hline & $\mathbf{K}$ & 27.22 & 26.20 & 1.20 & 26.9 & $2.59 \%$ & 26.9 & $2.59 \%$ \\
\hline & Cd & 3.13 & 0.01 & 0.02 & 0.01 & Negligible & 0.01 & Negligible \\
\hline & $\mathbf{U}$ & 0.00 & 4.27 & 0.04 & 4.35 & $1.97 \%$ & 4.35 & $1.97 \%$ \\
\hline \multirow{4}{*}{ 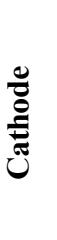 } & $\mathbf{L i}$ & 0.00 & $<0.0028$ & & 0.00 & Negligible & 0.00 & Negligible \\
\hline & $\mathbf{K}$ & 0.00 & $<0.007$ & & 0.00 & Negligible & 0.00 & Negligible \\
\hline & Cd & 100.00 & 100.00 & & 100.00 & $0.00 \%$ & 100.00 & $0.00 \%$ \\
\hline & $\mathbf{U}$ & 0.00 & 0.00 & & 0.00 & Negligible & 0.00 & Negligible \\
\hline
\end{tabular}

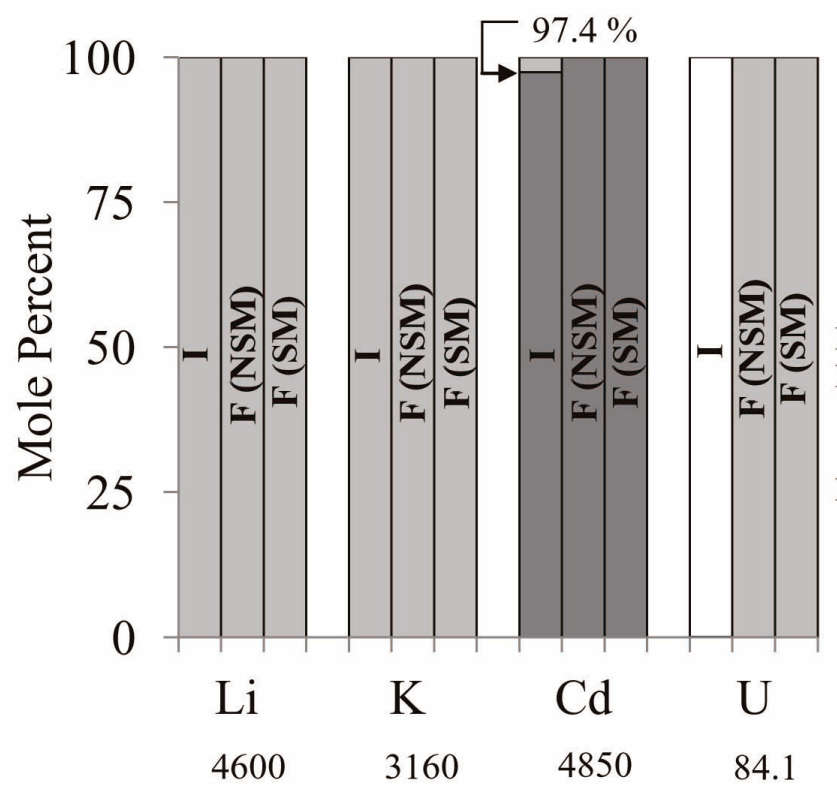

$\square$ Anode

$\square$ Electrolyte

$\square$ Cd Pool

I: Initial distribution

F (SM): Final distribution employing stoichiometric method

F (NSM): Final distribution using non-stoichiometric method

Fig. 3. Initial and Computed Species Distributions Throughout the ER for the Case 1. Bars are Grouped According to Element. The Total Amount of Each Element (in Moles) is Displayed under the Element name. Note: Each Element has a Different Population in the ER, so Each Column Group is Scaled Differently.

population greater than 0.001 mole.

The SM and the NSM compared well to the experimental data reported by Vaden, as listed in Table 4. In addition, the SM and NSM predictions match the values Vaden reported from his SM implementation. It should be mentioned that the anode initially contained 84.08 moles of $\mathrm{U}$, and was completely consumed over the course of the experiment.

Fig 3 is a graphical representation of the results presented in Table 4. It can be seen that both the $\mathrm{Li}$ and $\mathrm{K}$ remain in the salt as chlorides. It can also be deduced that the $\mathrm{U}$ initially in the anode fully reacts with the $\mathrm{Cd}$ 


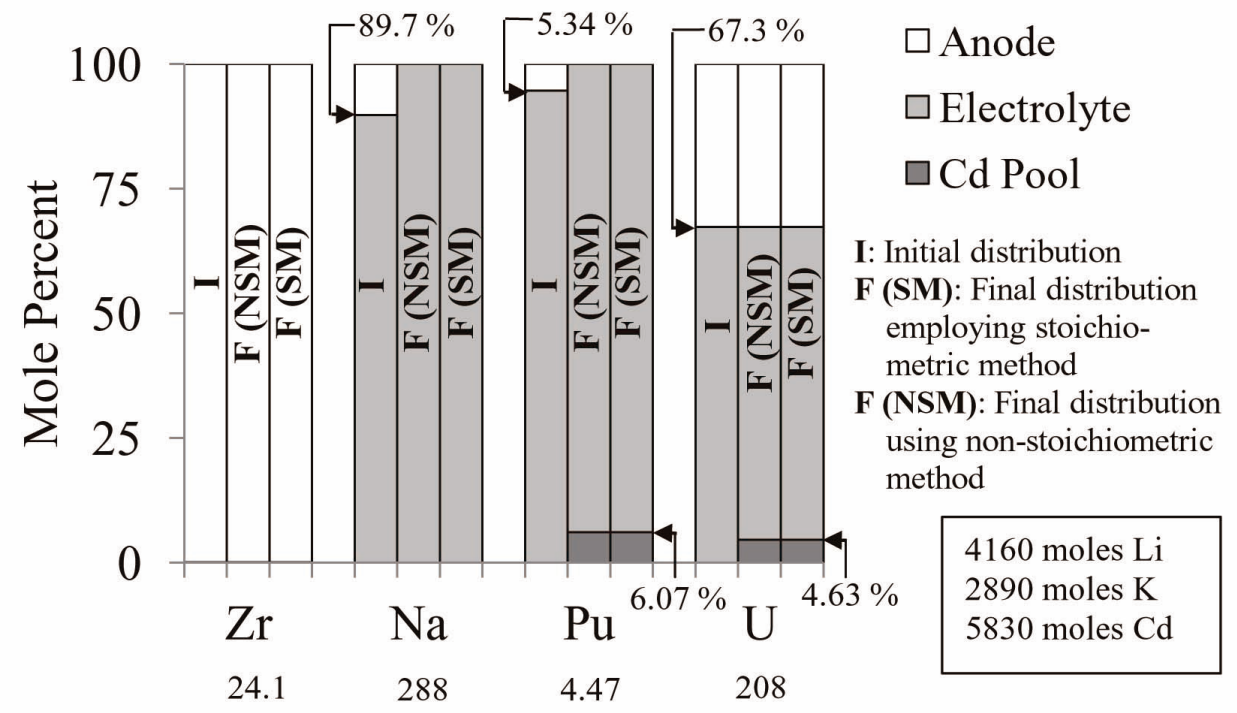

Fig. 4. Initial and Computed Species Distributions Throughout the ER for Case 2. The Total Amount of Each Element (in Moles) is Displayed under the Element Name. For Elements not Plotted, the Total Amount of Each Element (in Moles) is shown in the Bottom Right Corner.

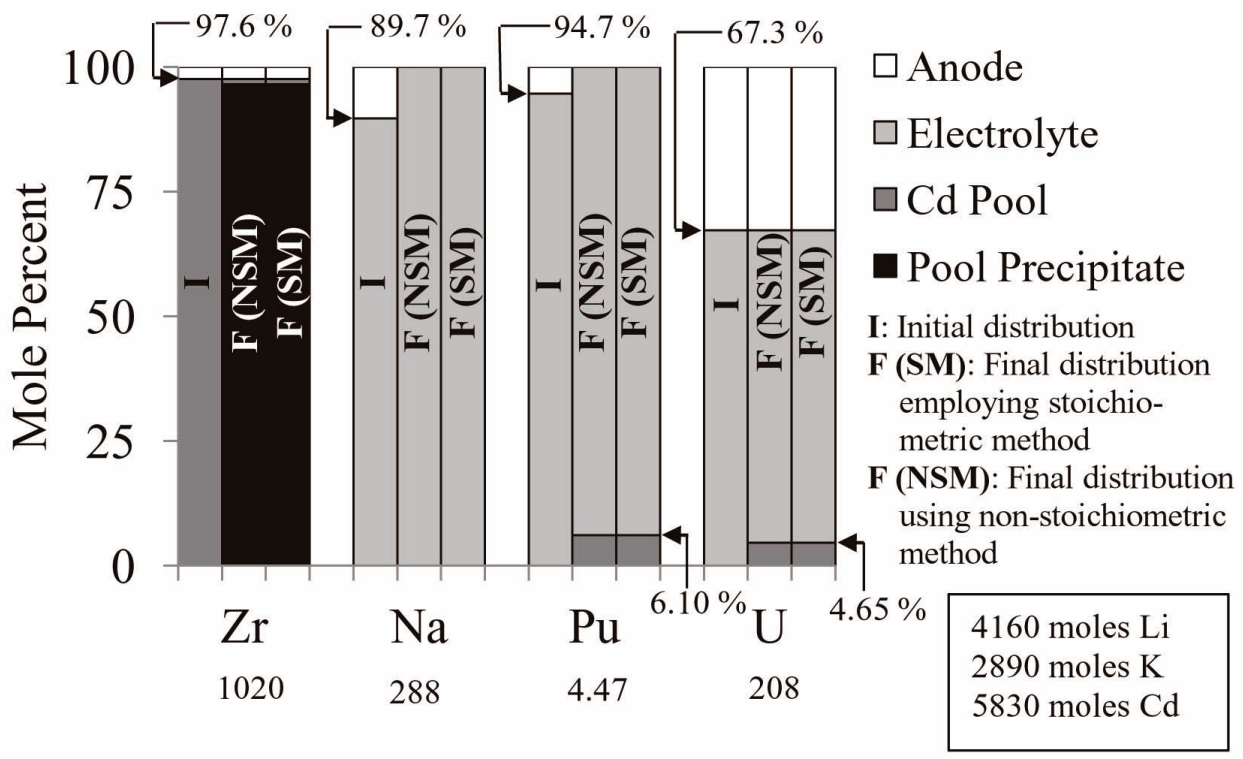

Fig. 5. . Initial and Computed Species Distributions Throughout the ER for Case 3. The Total Amount of Each Element (in Moles) is Displayed under the Element Name. For Elements not Plotted, the Total Amount of Each Element (in Moles) is shown in the Bottom Right Corner.

in the electrolyte, causing the $\mathrm{U}$ to become dissolved in the salt as $\mathrm{UCl}_{3}$ and the $\mathrm{Cd}$ to fall into the pool. Both methods performed nearly identically.

Further cross validation demonstrated that both methods also converge to the same solution using more realistic cases based on the ER run data. The results of the cross validation can be seen in Figs. 4 and 5. In both figures, only four of the seven elements are plotted, because Li, $\mathrm{Cd}$ and $\mathrm{K}$ remain at their initial locations.

The initial and final elemental distributions for Case 2 
can be seen in Fig 4. In that figure, one can see that all of the $\mathrm{Zr}$ remains in the anode, while the $\mathrm{U}$ in the salt reacts with the $\mathrm{Na}$ and $\mathrm{Pu}$ in the anode. That reaction causes the $\mathrm{Na}$ and $\mathrm{Pu}$ to dissolve in the electrolyte as their salts. The reaction also forms $\mathrm{U}$ metal, which falls into the $\mathrm{Cd}$ Pool. The $\mathrm{U}$ that is in the pool then reacts with the $\mathrm{PuCl}_{3}$ in the salt, causing $\mathrm{Pu}$ to enter into the pool. This prediction agrees with reports that sodium bond material completely dissolves when a fresh anode is inserted into the Mk-IV [7]. The final $\mathrm{U}$ to $\mathrm{Pu}$ ratio in the pool agrees somewhat with the only published experimental measurements of $\mathrm{U}$

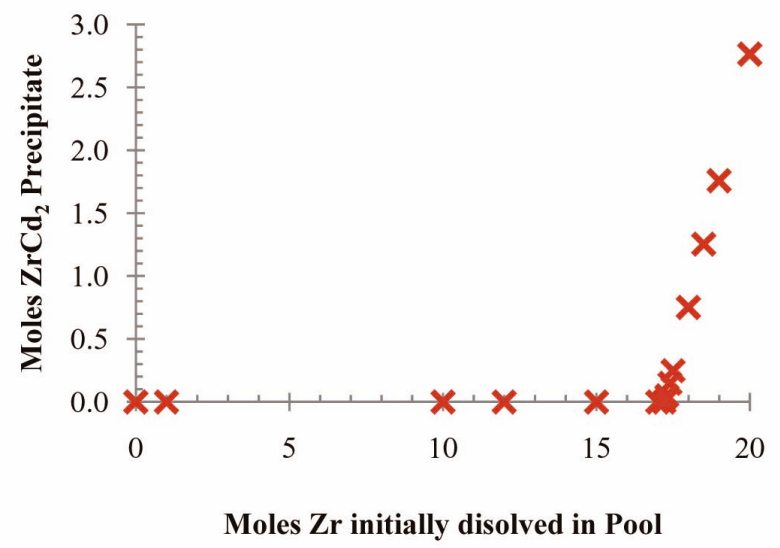

Fig. 6. $\mathrm{ZrCd}_{2}$ Precipitate Formation as a Function of Initial $\mathrm{Zr}$ Loading. and $\mathrm{Pu}$ concentration in the pool during a direct transport run that could be located [24]. In both cases, the amount of $U$ dissolved in the pool vastly exceeds the amount of $\mathrm{Pu}$ in the pool. This agreement is encouraging. Case 3 did not differ much from Case 2, except that most of the $\mathrm{Zr}$ in the pool precipitated with none entering the electrolyte or affecting the anode $\mathrm{Zr}$ population. This can be seen in Fig 5.

The intermediate cases (with $\mathrm{Zr}$ loadings that were greater than Case 2 and less than Case 3 ) had similar results to Cases 2 and 3-except that the amount of precipitate varied with the amount of $\mathrm{Zr}$ initially dissolved in the pool. As the zirconium in the pool never entered the salt, it simply obeyed the relationship shown in Eq. (14) when it was above its solubility limit. Given the $\mathrm{Cd}$ content of the pool of 5830 moles and the solubility limit for $\mathrm{Zr}$ shown in Table 3, one would expect $\mathrm{ZrCd}_{2}$ to start forming after 17 moles of $\mathrm{Zr}$ are added to the system. This is shown to be the case in Fig. 6 .

The sensitivity of Case 3 to activity coefficients whose values were questionable was small. The largest relative effects for each input parameter are shown in Figs. 7a and 7b. All absolute effects in other outputs from the model were small. It can be seen in the two plots that the largest absolute effect introduced to the system due to any error in these three activity coefficients is smaller than 0.015 moles. These values are shown in Figs. $7 \mathrm{a}$ and $7 \mathrm{~b}$. Considering that the cadmium pool consists of 5830 moles of material, and the maximum effect of the activity coefficient of sodium produces a change of 0.014 moles, it is clear that the effect of the activity coefficient is smallabout $3 \mathrm{ppm}$. In addition, the differences due to the zirconium activity coefficient changing are extremely

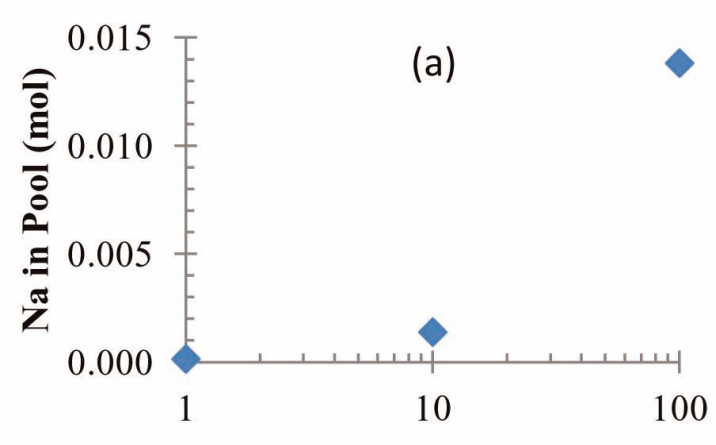

Activity Coefficient of $\mathrm{Na}$ in Salt

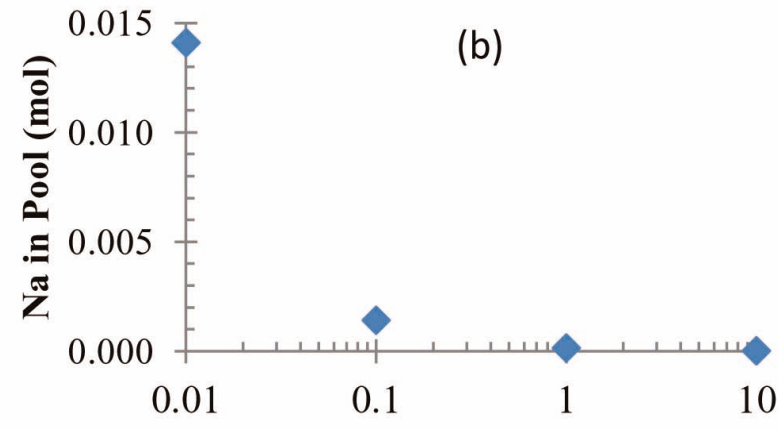

Activity Coefficient of $\mathrm{Na}$ in Pool

Fig. 7. (a) Effect of Activity Coefficient of Na in salt; (b) Effect of Activity Coefficient of Na in Pool. Note that the Greatest Effect of Changing the Activity Coefficient of $\mathrm{Zr}$ in the Pool was always well Below the Code's Convergence Tolerance. 
small (below $10^{-7}$ moles). Thus, the estimation of the activity coefficients should have little effect on the accuracy.

The agreement between the SM and the NSM in the cases run is in contrast to the results reported by Vaden [9]. This is likely because the method presented in this paper forces the SM and the NSM to account for the fact that the anode and pool never come in contact. This is in line with the reported hypothesis that the NSM implementation failed due to its presumption of contact between the pool and the anode [9].

\section{CONCLUSIONS}

To improve the computational model for electrorefining of spent metal fuel, stoichiometric and non-stoichiometric methods for calculating chemical equilibrium states have been analyzed. A variety of cases were considered with different initial ER states and computed using the two methods. Both methods predicted values for one case that remained well within the $95 \%$ confidence intervals for experimental data reported by Vaden [9]. Additionally, results from other cases are reasonable and reflect observations. Both models predicted that $\mathrm{Na}$ dissolves into the salt, as observed. The models also predicted that the amount of $\mathrm{U}$ in the $\mathrm{Cd}$ pool vastly exceeds $\mathrm{Pu}$. For these cases, the results are insensitive to any error introduced by estimated activity coefficients. The maximum error attributable to the estimation of the activity coefficients was found to be $3 \mathrm{ppm}$ change in mole fraction.

\section{ACKNOWLEDGEMENTS}

The authors would like to thank Drs. Michael F. Simpson and Tae-Sic Yoo of the Pyroprocessing Technology Dept. at Idaho National Laboratory for sharing their expertise in the preparation of this work. This work was in part supported by the Russell Family Foundation.

\section{REFERENCES}

[1] S. M. Stacy, Proving the Principle: A History of the Idaho National Engineering and Environmental Laboratory, 19491999, p. 262, Idaho Operations Office of the Department of Energy, Idaho Falls, Idaho (2000).

[2] R. W. Benedict,, C. Solbrig, B. Westphal, et al., "Pyroprocessing Progress at Idaho National Laboratory," ANS Global Conference, Boise, ID (2007).

[3] S. X. Li, and M. F. Simpson, "Anodic Process of Electrorefining Spent Driver Fuel in Molten LiCl-KCl$\mathrm{UCl}_{3} / \mathrm{Cd}$ System," Minerals and Metallurgical Processing, 22,4, 192 (2005).

[4] H. Nawada and N. Bhat, "Thermochemical modeling of Electrotransport of Uranium and Plutionum in an Electrorefiner," Nuclear Engineering and Design, 179, 7599 (1998).

[5] T. Murakami and T. Kato, "Electrochemical Behavior of $\mathrm{Zr}$ on a Liquid Cd Electrode in LiCl-KCl Eutectic Melts,"
Journal of the Electrochemical Society, 155,7, E90-E95 (2008).

[ 6 ] T. Koyama, T. R. Johnson, and D. F. Fischer. "Distribution of actinides in molten chloride salt/cadmium metal systems," Journal of Alloys and Compounds, 189, 37-44 (1992).

[7] J. Ackerman, "Chemical Basis for Pyrochemical Reprocessing of Nuclear Fuel," Industrial \& Engineering Chemistry Research, 30, 141-145 (1991).

[8] J. Ackerman, "PYRO, A System for Modeling Fuel Reprocessing," Transactions of the American Nuclear Society, 60, 168-169 (1989).

[9] D. Vaden, "Fuel Conditioning Facility Electrorefiner Process Model," Separation Science and Technology, 41, 2003-2012 (2006).

[10] D. Vaden, "Fuel Conditioning Facility Electrorefiner Model Predictions Versus Measurements," Separation Science and Technology, 43,9, 2684-2694 (2008).

[11] W. Smith and R. Missen, Chemical Reaction Equilibrium Analysis: Theory and Algorithms, John Wiley \& Sons Inc, New York (1992).

[12] R. O. Hoover, S. Phongikaroon, M. F. Simpson, et al., "Development of Computational Models for the Mark-IV Electrorefiner-Effect of Uranium, Plutonium, and Zirconium Dissolution at the Fuel Basket-Salt Interface," Nuclear Technology, 171,2, 276-284 (2010).

[13] R. Hoover, S. Phongikaroon, S. Li, M. Simpson, and T. Yoo, "A Computational Model of the Mark-IV Electrorefiner: Phase I: Fuel Basket/Salt Interface," Journal of Engineering for Gas Turbines and Power, 131, 054503-1 (2009).

[14] V. Kress, "On the Mathematics of Associated Solutions," American Journal of Science, 303, 708-712 (2003).

[15] J. J. Roy, L. F. Grantham, D. L. Grimmett, et. al. "Thermodynamic Properties of $\mathrm{U}, \mathrm{Np}, \mathrm{Pu}$, and $\mathrm{Am}$ in Molten LiCl-KCl Eutectic, and Liquid Cadmium," Journal of the Electrochemical Society, 143,8, 2487 (1996).

[16] R. Ahluwalia and T. Hua, "Electrotransport of Uranium from a Liquid Cadmium Anode to a Solid Cathode," Nuclear Technology, 140, 41-50 (2002).

[17] L. Pancratz, "Thermodynamic Properties of Halides", Bulletin 674,US Dept of Interior, Bureau of Mines Washington, D.C. (1984).

[18] J. Fuger, V. Parker, W. Hubbard, et al, "The Chemical Thermodynamics of Actinide Elements and Compounds, Part 8, The Actinide Halides," IAEA, Vienna Austria (1983).

[19] R. K. Ahluwalia, T. Q. Hua, and H. K. Geyer, "Removal of Zirconium in Electrometallurgical Treatment of Experimental Breeder Reactor II Spent Fuel," Nuclear Technology, 133, 103-118 (2001).

[20] P. Masset, D. Bottomley, R. Konings, et al., "Electrochemistry of Uranium in Molten LiCl-KCl Eutectic," Journal of the Electrochemical Society, 152,6, A1109 (2005).

[21] H. Bartlett, A. Neethling, and P. Crother, "Thermodynamic properties of sodium + cadmium and sodium + indium liquid alloys from electromotive force measurements," $J$. Chemical Thermodynamics, 2,4, 523-534(1970).

[22] R. Ahluwalia, T. Q. Hua, and H. K. Geyer, "Behavior of Uranium and Zirconium in Direct Transport Tests with Irradiated EBR-II Fuel," Nuclear Technology, 126,3, 289302 (1999).

[23] J. A. Plambeck, Encyclopedia of Electrochemistry of the 
Elements, Volume X, Fused Salt Systems; Bard, A.J. (ed.), Chapter 2, Marcel Dekker, NewYork, (1976).

[24] S. Li, D. Vaden, R. Mariani, and T. Johnson, "Experimental
Observations on the Role of the Cadmium Pool in MarkIV ER," ANS Embedded Topical Meeting Spent Fuel and Fissile Material, San Diego, CA, (2000). 